\title{
Inhibition Of Corrosion Of Carbon Steel In Well Water By Natural Jeera Dye $-\mathbf{Z n}^{2+}$ System
}

\author{
S.Meena ${ }^{1}$, G.Panchavarnam ${ }^{1}$ \& R.K.Kowsalya ${ }^{1}$,C.Mary Anbarasi ${ }^{2}$ \\ ${ }^{1}$ Research Department of Chemistry, Sakthi College of Arts and Science for Women, \\ Oddanchatram -624619 \\ ${ }^{2}$ PG\& Research Department of chemistry, Jayaraj Annapackiam College for Women, \\ Periyakulam -625601
}

\begin{abstract}
The inhibition of corrosion behaviour of carbon steel in Well water has been studied by the anticorrosion behaviour of the natural Jeera dye (JD) and $\mathrm{ZnSO}_{4}$ system. Results Obtained by Weight loss study shows $98 \%$ Maximum Inhibition efficiency at $10 \mathrm{ml}$ of Jeera dye Extract and 50ppm of $\mathrm{ZnSO}_{4}$. Synergistic parameters suggest that a synergistic effect existing between Jeera dye extract and $\mathrm{Zn}^{2+}$.Statistical study of " $\mathrm{F}$ " test also revealed this effect. The Surface analysis was performed by Scanning electron microscope technique ( SEM )which was confirmed, the existence of an inhibitor molecules on the metal surface.FTIR Spectra revealed that the protective film consist of a complex formed between the active principle of the Jeera dye extract and $\mathrm{Zn}^{2+}$.
\end{abstract}

Keywords: corrosion inhibition, carbon steel, weight loss study, F-Test, SEM, FTIR

\section{INTRODUCTION}

Corrosion is the deterioration of the metal by the chemical reaction when come in contact with the atmosphere or moisture ${ }^{1}$.The use of inhibitors is one of the best options of protecting metals against corrosion in various fields of application as acid pickling and acid descaling ${ }^{2}$. The known hazardous effects of most synthetic corrosion inhibitors are the motivation for the use of some natural products. So the environmentally friendly inhibitors are chosen for their non-toxic, biodegradable and readily available in nature. Several investigations showed that different media for different metal using naturally occurring substances as corrosion inhibitors used. In those studies some of them found to inhibit corrosion in well water \& sea water ${ }^{3-5}$ as their medium. For example, Corrosion inhibition of Carbon steel in well water by vitexnegundo extract has been studied ${ }^{6}$. The Corrosion effects of Allium sativum (Garlic) extract have been reported ${ }^{7}$. Banana peel has been used as corrosion inhibitor for carbon steel in sea water ${ }^{8}$. The inhibition efficiency (IE) of an aqueous extract of Beetroot in controlling corrosion of carbon steel in well water has also been reported ${ }^{9}$. Pisonia Alba has been reported as corrosion inhibitor for carbon steel in well water ${ }^{10}$. The present study aimed to discuss the inhibitive performance of natural Jeera dye extract as eco-friendly corrosion inhibitor for carbon steel in well water by using weight-loss, syngeristic effect, and FTIR \&SEM methods.

\section{EXPERIMENTAL}

2.1 Preparation of the Carbon steel specimens: Carbon steel specimens $(0.026 \% \mathrm{~S}, 0.06 \%$ $\mathrm{P}, 0.4 \% \mathrm{Mn}$, and $0.1 \% \mathrm{C}$ and rest iron) of the dimensions $1.0 \times 4.0 \times 0.2 \mathrm{~cm}$ were polished to 
a mirror finish, degreased with trichloroethylene, and used for Weight-loss and surface examination studies.

2.2 Preparation of Jeera dye extract: $10 \mathrm{gm}$ of Jeera powder was weighed \& boiled with double distilled water. The golden yellow colour dye of Jeera was filtered to remove suspended impurities \& made up to $100 \mathrm{ml}$. The Jeera Dye (JD) was used as corrosion inhibitor in the present study.

\subsection{Weight-Loss method:}

Determination of Surface area of the specimens: The length, breadth and the thickness of carbon steel specimens and the radius of the holes were determined with the help of vernier calipers of high precision and the surface areas of the specimens were calculated.

Weighing the specimens before and after Corrosion: All the weighing of the carbon steel specimens before and after corrosion was carried out using shimadzu balance-AY62.

Determination of corrosion rate :The weighed specimen in duplicate were suspended by means of glass hooks in $100 \mathrm{ml}$ beaker containing $100 \mathrm{ml}$ various test solutions and after 24 hours of immersion, the specimens were taken out, washed in running water, dried and weighed. From the change in weights of the specimen, corrosion rates were calculated using the following relationship.

Loss in weight (mg) x1000

Corrosion Rate $(\mathrm{mm} / \mathrm{y})=$ $X 0.0365 / d$

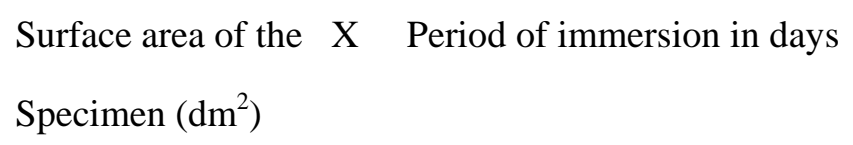

Corrosion inhibition efficiency (IE) was then calculated using the equation

$$
\mathrm{IE}=100\left[1-\left(\mathrm{W}_{2} / \mathrm{W}_{1}\right)\right] \%
$$

Where,

$$
\begin{aligned}
& \mathrm{W}_{1}=\text { Corrosion rate }(\mathrm{mm} / \mathrm{yr}) \text { in absence of inhibitor. } \\
& \mathrm{W}_{2}=\text { Corrosion rate }(\mathrm{mm} / \mathrm{yr}) \text { in presence of inhibitor } \\
& \mathrm{d}=\text { Density of the metal }
\end{aligned}
$$


2.4 Synergism parameters: Synergism parameters are indication of synergistic effect existing between two inhibitors $(1,2)$.

Synergism Parameters were calculated using the relation

$$
\begin{aligned}
S_{1}= & \left(1-\Theta_{1+2 / 1}-\Theta_{1+2}^{\prime}\right) \text { Where } \\
& \Theta_{1+2}=\left(\Theta_{1}+\Theta_{2}\right)-\left(\Theta_{1} \times \Theta_{2}\right) \\
& \Theta_{1}=\text { inhibition efficiency of substance } 1 \\
& \Theta_{2}=\text { inhibition efficiency of substance } 2 \\
& \Theta_{1+2}^{\prime}=\text { combined inhibition efficiency of substance } 1 \& 2
\end{aligned}
$$

2.5 F- test: F- test was carried out to investigate whether the synergistic effect existing between Jeera dyes extract and $\mathrm{Zn}^{2+}$ system statistically significant or $\operatorname{not}^{11}$.

2.6 Surface Examination Study: The carbon steel specimens were immersed in various test solutions for a period of one day. After one day, the specimens were taken analysed by surface analysis technique, namely, infrared spectroscopy \& SEM Analysis ${ }^{10}$.

FTIR Spectra : These spectra were recorded with the Perkin - Elmer 1600 spectrophotometer. The FTIR spectrum of the protective film was recorded by ; carefully removing the film mixed it with $\mathrm{KBr}$ and making the pellet.

SEM Study: The surface morphology measurements of the carbon steel were examined by using JEOL JSM 6390 model. All SEM micrographs of carbon steel are taken at a magnification of $X=1000^{11}$.

\section{RESULTS AND DISCUSSION}

\subsection{Analysis of the weight loss method :}

The calculated inhibition efficiencies (IE) of jeera dye in controlling the corrosion of carbon steel immersed in well water both in the absence and presence of zinc ion have been tabulated in table 1 to 3 . It is observed from table 1 shows the inhibition efficiency $46 \%$ for $2 \mathrm{ml}$ of Jeera dye extract as the concentration of the inhibitor extract increases the inhibition efficiency also increases. The calculated values indicate the ability of jeera dye to be a good corrosion inhibitor. The inhibition efficiency is found to be enhanced in the presence of zinc ion. The formulation consisting of $10 \mathrm{ml}$ of JD \& 50ppm of $\mathrm{Zn}^{2+}$ offers $98 \%$ inhibition efficiency. 
Table 3.1.1: Corrosion rates (CR) of carbon steel in well water in the absence and presence of inhibitors and the inhibition efficiencies obtained by weight -loss method.

Inhibitor system: JD extract $+\mathrm{Zn}^{2+}(0 \mathrm{ppm})$

Period of immersion: 1 day

\begin{tabular}{|c|c|c|c|}
\hline $\begin{array}{c}\text { Jeera dye extract } \\
(\mathrm{ml})\end{array}$ & $\begin{array}{c}\mathrm{Zn}^{2+} \\
(\mathrm{ppm})\end{array}$ & $\begin{array}{c}\mathrm{CR} \\
(\mathrm{mm} / \mathrm{y})\end{array}$ & $\begin{array}{c}\text { IE } \\
\%\end{array}$ \\
\hline 0 & 0 & 0.0695 & - \\
\hline 2 & 0 & 0.0375 & 46 \\
\hline 4 & 0 & 0.0319 & 54 \\
\hline 6 & 0 & 0.0284 & 59 \\
\hline 8 & 0 & 0.0271 & 61 \\
\hline 10 & 0 & 0.0264 & 62 \\
\hline
\end{tabular}

Table 3.1.2 :

Inhibitor system: Jeera Dye (JD) $+\mathrm{Zn}^{2+}(25 \mathrm{ppm}) \quad$ Period of immersion: 1 day.

\begin{tabular}{|c|l|l|l|}
\hline $\begin{array}{c}\text { Jeera } \\
\text { dye } \\
\text { ml }\end{array}$ & $\begin{array}{l}\mathrm{Zn}^{2+} \\
\mathrm{ppm}\end{array}$ & $\begin{array}{c}\mathrm{CR} \\
\mathrm{mm} / \mathrm{y}\end{array}$ & $\begin{array}{l}\mathrm{IE} \\
\%\end{array}$ \\
\hline 0 & 25 & 0.0556 & 20 \\
\hline 2 & 25 & 0.0243 & 65 \\
\hline 4 & 25 & 0.0201 & 71 \\
\hline 6 & 25 & 0.0187 & 73 \\
\hline 8 & 25 & 0.0173 & 75 \\
\hline 10 & 25 & 0.0159 & 77 \\
\hline
\end{tabular}


Table

\begin{tabular}{|c|c|c|c|}
\hline $\begin{array}{c}\text { Jeera dye } \\
\mathrm{ml}\end{array}$ & $\begin{array}{c}\mathrm{Zn}^{2+} \\
\mathrm{ppm}\end{array}$ & $\begin{array}{c}\mathrm{CR} \\
\mathrm{mm} / \mathrm{y}\end{array}$ & $\begin{array}{c}\mathrm{IE} \\
\%\end{array}$ \\
\hline 0 & 50 & 0.0417 & 40 \\
\hline 2 & 50 & 0.0097 & 86 \\
\hline 4 & 50 & 0.0076 & 89 \\
\hline 6 & 50 & 0.0055 & 92 \\
\hline 8 & 50 & 0.0027 & 96 \\
\hline 10 & 50 & 0.0013 & 98 \\
\hline
\end{tabular}

3.1.3 :

Inhibito

r

system:

Jeera

dye(JD)

$+\mathrm{Zn}^{2+}$

$(50$

ppm)

Period

of immersion: 1 day.

\subsection{Influence of immersion period on the corrosion inhibition of carbon} steel in well water by $\mathrm{JD}+\mathrm{Zn}^{2+}$ system

The corrosion rates of carbon steel in the presence of the inhibitor system in well water for different durations of immersion are tabulated in table 3.2.1 
The IE of $10 \mathrm{ml} \mathrm{JD} \mathrm{50ppm} \mathrm{Zn}^{2+}$ system is found to decrease as the immersion period increases. This indicates that the protective film formed on the metal surface is unable to withstand the continuous attack of corrosive ions such as $\mathrm{Cl}^{-}$ion (665ppm) present in well water. There is competition on the anodic sites of the metal surface. A perusal of the results suggests that the formation of $\mathrm{FeCl}_{2}$ is favoured when compared with the formation of $\mathrm{Fe}^{2+}$ JD complex ${ }^{12,13 .}$

\begin{tabular}{|c|c|c|c|c|}
\hline $\begin{array}{c}\text { Jeera } \\
\text { dye } \\
\mathrm{ml}\end{array}$ & $\mathrm{Zn} \mathrm{n}^{2+}$ & $\begin{array}{c}\text { Immersion } \\
\text { Period } \\
\text { Days }\end{array}$ & $\begin{array}{c}\text { Corrosion } \\
\text { Rate } \\
\mathrm{mm} / \mathrm{y}\end{array}$ & $\begin{array}{c}\text { Inhibition } \\
\text { Efficiency } \\
\%\end{array}$ \\
\hline
\end{tabular}

Table 3.2.1: Influence of immersion period on the inhibition efficiency of the JD $(10 \mathrm{ml})$ $-\mathbf{Z n}^{2+}(50 \mathrm{ppm})$.

Corrosion rates $(\mathrm{CR})$ of carbon steel in well In the absence and presence of inhibitor system and the inhibition efficiencies obtained by the mass - loss method.

Inhibitor system: JD $(10 \mathrm{ml})+\mathrm{Zn}^{2+}(50 \mathrm{ppm})$. 


\begin{tabular}{|c|c|c|c|c|}
\hline 0 & 0 & 1 & 0.0695 & - \\
\hline 10 & 50 & 1 & 0.0013 & - \\
\hline 0 & 0 & 3 & 0.2318 & 72 \\
\hline 10 & 50 & 3 & 0.0649 & - \\
\hline 0 & 0 & 5 & 0.1252 & 70 \\
\hline 10 & 50 & 5 & 0.0375 & - \\
\hline 0 & 0 & 7 & 0.4823 & 48 \\
\hline 10 & 50 & 7 & 0.2507 & \\
\hline
\end{tabular}

\subsection{Influence of pH on inhibition efficiency of Jeera dye $+\mathrm{Zn}^{2+}$ system.}

Corrosion rates of carbon steel in well water in the presence of the inhibitor system at different $\mathrm{pH}$ and the IE are tabulated in table 3.3.1

At $\mathrm{pH} 8$, the IE of JD $\mathrm{Zn}^{2+}$ system is $67 \%$.when the $\mathrm{pH}$ is lowered to 6 (by the addition of dil. $\mathrm{H}_{2} \mathrm{SO}_{4}$ ). The IE decreases to 80 due to the attack of $\mathrm{H}^{+}$ion present in the acid. On protective film formed on the metal surface. When the $\mathrm{pH}$ decreased from 8 to 7 . The IE decreases from 67 to 61 . This is due to the fact that the protective film formed on the metal surface is broken by the attack of $\mathrm{H}^{+}$ion ${ }^{14-17}$.

Table 3.3.1: Influence of $\mathrm{pH}$ on the inhibition efficiency of $\mathrm{JD}(10 \mathrm{ml})-\mathrm{Zn}^{2+}(50 \mathrm{ppm})$.

Corrosion rates of carbon steel in well at different $\mathrm{pH}$ and the inhibition efficiencies obtained by the mass loss method.

Inhibitor system: JD (10ml) $-\mathrm{Zn}^{2+}(50 \mathrm{ppm})$.

Immersion period: 1 day.

\begin{tabular}{|l|l|l|l|l|}
\hline Jeera & $\mathrm{Zn}^{2+}$ & & Corrosion & IE \\
\hline
\end{tabular}




\begin{tabular}{|c|c|c|c|c|}
\hline $\begin{array}{c}\text { dye } \\
\mathrm{ml}\end{array}$ & $\mathrm{ppm}$ & $\mathrm{pH}$ & $\begin{array}{c}\text { Rate } \\
\mathrm{mm} / \mathrm{y}\end{array}$ & $\%$ \\
\hline 0 & 0 & 7 & 0.1808 & - \\
\hline 10 & 50 & 7 & 0.0705 & 61 \\
\hline 0 & 0 & 8 & 0.1716 & - \\
\hline 10 & 50 & 8 & 0.0566 & 67 \\
\hline 0 & 0 & 6 & 0.1205 & - \\
\hline 10 & 50 & 6 & 0.0241 & 80 \\
\hline
\end{tabular}

\subsection{Synergism parameters}

Synergism parameters have been calculated to evaluate the synergistic effect existing between two inhibitors ${ }^{18,19}$. when the value of synergism parameter is greater than 1 synergistic effect exists. synergistic effect can be calculated using the following equation.

$$
1-\theta_{1+2}
$$

Synergism parameters $\left(\mathrm{S}_{1}\right)=$

$$
1-\theta_{1+2}
$$

Where $\quad \theta_{1+2}=\left(\theta_{1}+\theta_{2}\right)-\left(\theta_{1} \theta_{2}\right)$

$$
\begin{aligned}
& \theta_{1}=\text { inhibition efficiency of substance } 1 . \\
& \theta_{2}=\text { inhibition efficiency of substance } 2 .
\end{aligned}
$$

$\Theta{ }^{\prime}{ }_{1+2}=$ inhibition efficiency of combined substance $1 \& 2$.

Where, $\theta=$ surface coverage $=\mathrm{IE} \% / 100$

The synergism parameters are given in table IV.6. It is observed that the value of synergism parameter is greater than1.This suggests that a synergistic effect exists between JD and $\mathrm{Zn}^{2+}$ indicating synergistic effect existing between various volumes of JD and $\mathrm{Zn}^{2+}$.It is also interesting to note that the values of $S_{1}$ are slightly smaller in the case of $50 \mathrm{ppm}$ of $\mathrm{Zn}^{2+}$. When compared with $25 \mathrm{ppm}$ of $\mathrm{Zn} 2^{+}$. This is in agreement with inhibition efficiencies 
obtained by weight loss method. Thus the values of synergism parameter give a synergism existing between two inhibitors.

Table 3.4.1: Synergism parameters derived from inhibition efficiencies of $\mathrm{JD}-\mathrm{Zn}^{2+}(25$ ppm) and (50 ppm) system.

\begin{tabular}{|c|c|c|c|}
\hline \multirow{2}{*}{$\begin{array}{c}\text { Jeera dye } \\
\text { ml }\end{array}$} & \multicolumn{2}{|c|}{$\mathrm{Zn}^{2+}$} & \multirow{2}{*}{$\mathrm{S}_{1}$} \\
\cline { 2 - 4 } 0 & $0 \mathrm{ppm}$ & $25 \mathrm{ppm}$ & - \\
\hline 2 & - & 20 & 1.2342 \\
\hline 4 & 46 & 65 & 1.2689 \\
\hline 6 & 54 & 71 & 1.2148 \\
\hline 8 & 61 & 73 & 1.2480 \\
\hline 10 & 62 & 75 & 1.3217 \\
\hline
\end{tabular}

\begin{tabular}{|c|c|c|c|}
\hline \multirow{2}{*}{$\begin{array}{c}\text { Jeera dye } \\
\mathrm{ml}\end{array}$} & \multicolumn{2}{|c|}{$\mathrm{Zn}^{2+}$} & \multirow{2}{*}{$\mathrm{S}_{1}$} \\
\cline { 2 - 4 } 0 & $0 \mathrm{ppm}$ & $50 \mathrm{ppm}$ & - \\
\hline 2 & - & 40 & 2.3142 \\
\hline 4 & 46 & 86 & 2.5090 \\
\hline 6 & 54 & 89 & 3.075 \\
\hline 8 & 59 & 92 & 5.85 \\
\hline 10 & 61 & 96 & 11.4 \\
\hline
\end{tabular}

\subsection{F-Test}

It is observed from the table that the calculated $\mathrm{F}$ value 19.0578 is greater than the table value 5.32 for 8 degree of freedom at 0.05 level of significance. Hence it is concluded that the synergistic effect existing between jeera dye extract and $50 \mathrm{ppm}$ of $\mathrm{Zn}^{2+}$ is statistically significant. $^{11}$ 
Table 3.5.1: Distribution of F-Value between the inhibition efficiencies of various concentrations of JD (0ppm of $\left.\mathrm{Zn}^{2+}\right)$ and the inhibition efficiencies of JD in the presence of $25 \mathrm{ppm}$ of $\mathrm{Zn}^{2+}$ and $50 \mathrm{ppm}$ of $\mathrm{Zn}^{2+}$.

\begin{tabular}{|l|l|l|l|l|l|l|}
\hline $\begin{array}{l}\mathrm{Zn}^{2+} \\
(\mathrm{ppm})\end{array}$ & $\begin{array}{l}\text { Source } \\
\text { of } \\
\text { variance }\end{array}$ & $\begin{array}{l}\text { Sum of } \\
\text { squares }\end{array}$ & $\begin{array}{l}\text { Degree } \\
\text { of } \\
\text { freedom }\end{array}$ & $\begin{array}{l}\text { Mean } \\
\text { square }\end{array}$ & $\begin{array}{l}\text { F- } \\
\text { Value }\end{array}$ & Level of significance \\
\hline 0 & Between & 125 & 1 & 125 & & \\
\cline { 1 - 4 } 25 & Within & 258 & 8 & 32.25 & 3.8759 & $\mathrm{p}<0.05$ \\
\hline 0 & Between & 640.82 & 1 & 640.82 & & \\
\hline 50 & Within & 269 & 8 & 33.625 & 19.0578 & $\mathrm{p}>0.05$ \\
\hline
\end{tabular}

\subsection{Analysis of FTIR spectra:}

The active principle in an aqueous extract of Jeera dye is cuminaldehyde. The golden yellow colour of the extract is due to cuminaldehyde. The main constituent of Jeera powder is cuminaldehyde $^{20}$. The structure of cuminaldehyde is shown in figure1. The cuminaldehyde extract was evaporated to dryness to set a solid mass. FTIR spectrum is shown in fig.3.6 a. Suggest, the $\mathrm{C}=\mathrm{O}$ stretching frequency appears at $1600.92 \mathrm{~cm}^{-1}$.

The FTIR spectrum of the protective film formed on the surface of the metal after immersed in the solution containing 50ppm of $\mathrm{Zn}^{2+}$ and $10 \mathrm{ml}$ of JD shown in fig.3.6.b. The $\mathrm{C}=\mathrm{O}$ stretching .Frequency has decreased from $1600.92 \mathrm{Cm}^{-1}$ to $1109.07 \mathrm{Cm}^{-1}$. The $-\mathrm{OH}$ stretching Frequency appears at $3444.87 \mathrm{Cm}^{-1}$.The ring oxygen appeared at $970.19 \mathrm{Cm}^{-1}$.It has coordinated $\mathrm{Fe}^{2+}$ to form protective film on metal surface. The peak at $1360 \mathrm{Cm}^{-1}$ is due to $\mathrm{Zn}-\mathrm{O}$ stretching. Peak at $3444.87 \mathrm{Cm}^{-1}$ is due to $-\mathrm{OH}$ stretching. So it is concluded that $\mathrm{Zn}(\mathrm{OH})_{2}$ is formed on cathodic sites of the metal surface ${ }^{21-23}$.

\section{FTIR SPECTRA:}




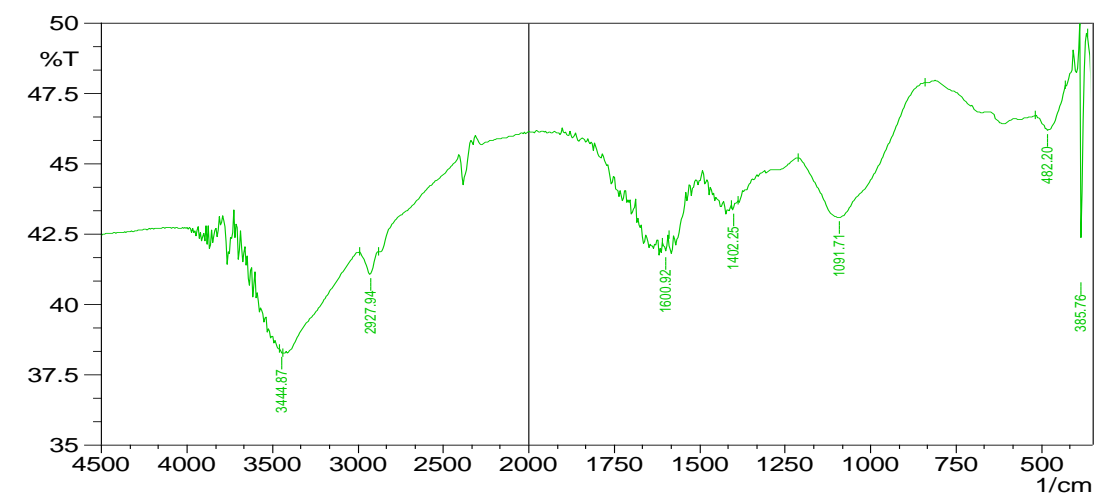

3.6(a)Pure JD

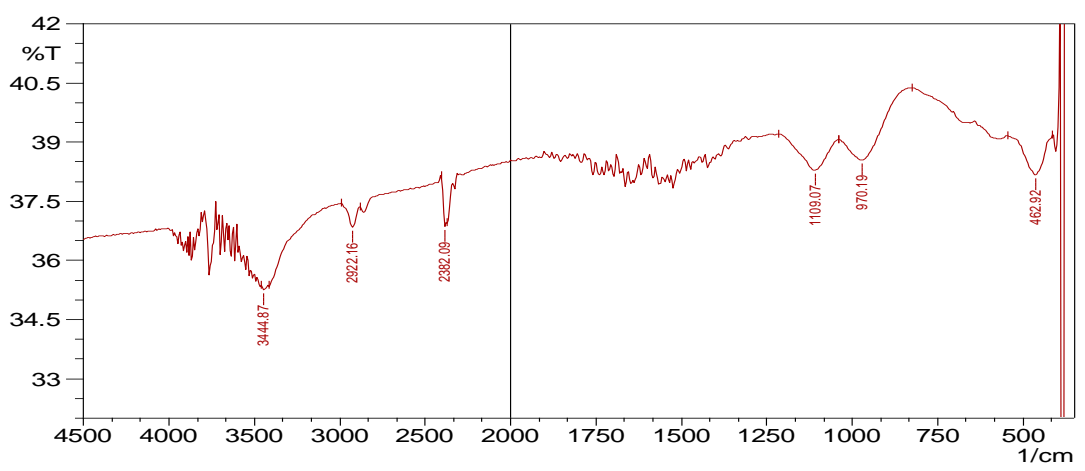

3.6 (b) Film formed on metal surface after immersion in well water containing $10 \mathrm{ml}$ of JD $50 \mathrm{ppm}$ of $\mathrm{Zn}^{2+}$.

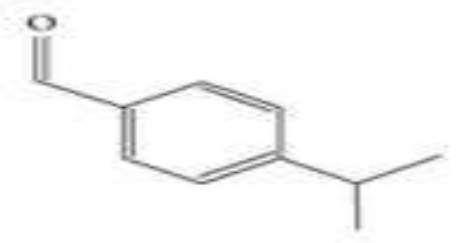

Fig.1 structure of Cuminaldehyde

\subsection{SEM analysis of metal surface}

SEM provides a pictorial representation of the surface to understand the nature of the surface film in the absence and presence of inhibitors and the extent of corrosion of carbon steel, the SEM micrographs of the surface are examined ${ }^{24 .}$ 
The SEM image of different magnifications (X 1000) of carbon steel specimen and carbon steel specimen immersed in well water for 1 day in the absence and presence of inhibitor system are shown in fig 3.7 as images ( $a, b$, and c) respectively.

The micrograph of polished carbon steel surface (control) in fig.3.7 images (a) illustrates the smooth surface of the metal. These shows the absence of any corrosion products formed on the metal surface.

The image 3.7(b) denotes the SEM micrographs of carbon steel surface immersed in well water. These show the type of rough surface characteristic of the uniform corrosion of the metal surface in well water, indicating in an inhibitor free solution, the surface is highly corroded.

The image 3.7 (c) confirms that in the presence of $10 \mathrm{ml}$ of JD \& $50 \mathrm{ppm}$ of $\mathrm{Zn}^{2+}$ mixture in well water, the rate of corrosion is suppressed, as can be seen from the decrease in corroded areas. This is due to the formation of insoluble complex (JD- $\mathrm{Zn}^{2+}$ inhibitor complex) formed on the metal surface of the carbon steel ${ }^{25}$

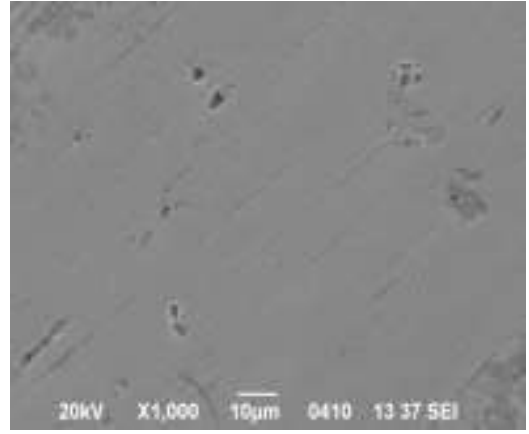

3.7.a) Polished Carbon steel

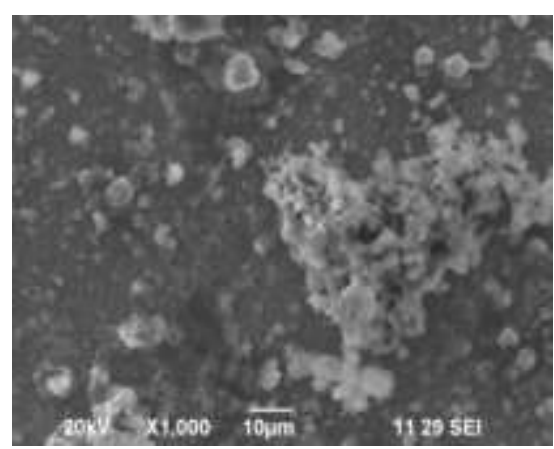

3.7.b) Carbon steel immersed in well water

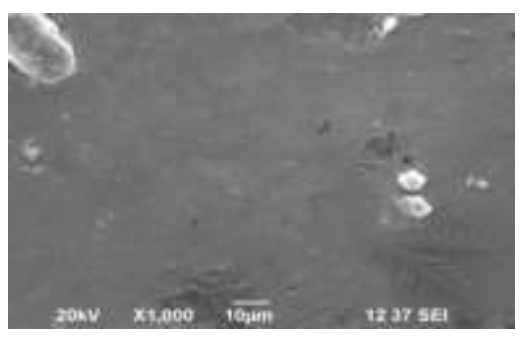

3.7.c) Carbon steel immersed in well water containing $10 \mathrm{ml}$ of JD- 50ppm of $\mathrm{Zn}^{2+}$. 


\section{CONCLUSION}

The inhibition efficiency (IE) of Jeera Dye $-\mathrm{Zn}^{2+}$ system in controlling corrosion of carbon steel in an aqueous solution containing $665 \mathrm{ppm} \mathrm{of} \mathrm{Cl}^{-}$has been evaluated by mass loss method. The present study leads to the following conclusion.

- Weight loss study reveals that the formulation consisting of $10 \mathrm{~mL}$ of JD and $50 \mathrm{ppm}$ of $\mathrm{Zn}^{2+}$ has $98 \%$ inhibition efficiency in controlling corrosion of carbon steel immersed in an aqueous solution containing $665 \mathrm{ppm}$ of $\mathrm{Cl}^{-}$.

- Synergistic parameters suggest that a synergistic effect exists between JD and $\mathrm{Zn}^{2+}$.

- The FTIR spectra reveal that the protective film consists of $\mathrm{Fe}^{2+}-\mathrm{JD}$ complex.

- The SEM micrograph confirms the formation of protective layer formed on the metal surface.

\section{REFERENCES}

1. J.Bhawsar; Pk Jain: P Jain: D Jagwani .Eco friendly corrosion inhibitors from natural plant extract: A review, proceeding National seminar on recent Trends in chemical and biological sciences ,2012.

2. Abdellahlaqhaili; AbdelhakHakiki; MahjoubaMossaddak; Maria Boudalia; Abdelkabir Bellaouchou; Abdellah

3. M.A Ameer,A.M.Fekry. Corrosion inhibition of mild steel by natural product compound. progress of Organic coatings,2011,71,343-349.

4. S.Leelavathi,R.Rajalakshmi.Dodonaeaviscose (L) Leaves extract as acid corrosion inhibitor for mild steel-A green approach. Journal of material and environmental science,2013,4(5)625-638.

5. S.Geeha,S.Lakshmi,K.Bharathi. Corrosion inhibition of aluminium in alkaline medium using vitexnegundo leaves extract.International journal of advanced scientific and technical research,2013,.3(3),258-268.

6. K.Anuradha,R.Vimala,B.Narayanasamy,J.A.Selvi and S.Rajendran,Chemical Engineering Communications,vol.195,no.3,pp.352-366,2008.

7. M.Sangeetha,S.Rajendran,J.Sathiyabama and P.Prabhakar,J. Nat.Prod.Plant Resour.,2012,2(5):601-610. 
8. G.R.H.Florence, A.N.Antony J.W.Sahayaraj, A.J.Amalraj, S.Rajendran, Indian J.Chem.Technol,12(2005)472.

9. Selvi JA, Rajendran S, Sri VG, Amalraj AJ,Narayanasamy .B,Corrosion inhibition by beet root extract .Portugaliae Electrochimica Acta .2009; 27:1-11.

10. P.Thirupathi,S.K.Selvaraj,A.John Amalraj ,B.R.Venkatraman, An aqueous extract of piosnia Alba as Eco-Friendly Corrosion Inhibitor for Carbon steel in Well Water. International Journal of Research and analytical Reviews, Volume -5, Issue-4, 2018;130-135.

11. J.Thomas paulraj, A.Sahaya raja, J.Sathiya bama, V.Prathipa study of Acalypha Indica Extract as a novel green inhibitor for carbon steel in aqueous medium ;IJGHC,2014 Sec.B;Vol 3,No.3,1034-1038.

12.S.K.selvaraj ,A.johnkennedy , A.Johnamalraj , S.Rajendran and N.Palaniswamy, corrosion reviews,22(2004)219.

13.S.Rajendran,S.MaryReenkala, Noreen Anthony and R.Ramaraj,corrosion science, $44(2002) 449$.

14.G.Ruba Helen Florence ,A.Noreen Anthony ,J.wilsonSahayaraj, A.JohnAmal Raj and SusaiRajendran, Indian journal of chemical technology, 12 July (2005)472-476.

15.Felicia rajammalselvarani, s. Santhamadharasi, 1. Wilson sahayaraj, A. John Amalraj and Susairajen, Bulletin of electrochemistry,20(12) Dec.(2004)561-565.

16.SusaiRajendran, S.MaryReenkala, Noreen Anthony and R.Ramaraj,corrosion science,44(10) Oct.(2002) 2243-2252.

17.Kanitsuguaramati, corrosion science, 43(10) Oct.(2001) 1985-2000.

18.S.Rajendran, A. Rosaly and S. Thangasamy, journal of material Education (2006) 219.

19.V.Johnsirani, S. Rajendran ,J.Sathiyabama, Bulgarian chemical communications, volume 44,Number 1(pp.41-51) 2012.

20.V.Johnsirani, J.Sathiyabama,P.Prabhakar, SusaiRajendran, Research Journal of chemical sciences vol.3 (2), 10-15, February (2013).

21.V.Johnsirani, J.Sathiyabama, SusaiRajendran, and A.Suriyapraba, international scholarly research network ISRN Corrosion vol 2012, article ID 574321, 9 pages.

22.V. Sribharathy and Susai RajendranCuminum cyminum Extracts as Eco-Friendly

Corrosion Inhibitor for Mild Steel in Seawater Volume 2013 ), Article ID 370802, 7 pages 
23. N. S. Iacobellis, P. Lo Cantore, F. Capasso, and F. Senatore, "Antibacterial activity of Cuminum cyminum L. and Carum carvi L. essential oils,” Journal of Agricultural and Food Chemistry, vol. 53, no. 1, pp. 57-61, 2005. View at Publisher • View at Google Scholar • View at Scopus

24..S. Agnesia Kanimozhi and S. Rajendran, "Inhibitive properties of sodium tungstate- $\mathrm{Zn}^{2+}$ system and its synergism with HEDP," International Journal of Electrochemical Science, vol. 4, pp. 353-368, 2009. View at Google Scholar

25.R. M. Silver stein, G. C. Bassler, and T. C. Morrill, Spectroscopic Identification of Organic Compound, vol. 95, John Wiley \& Sons, New York, NY, USA, 1986. 